\title{
Disadvantaged pre-schoolers attending day care in Salvador, Northeast Brazil have a low prevalence of anaemia and micronutrient deficiencies
}

\author{
Rebecca L Lander ${ }^{1}$, Karl B Bailey ${ }^{1}$, Alastair $G$ Lander $^{1}$, Abdulmonem A Alsaleh ${ }^{2}$, \\ Hugo C Costa-Ribeiro ${ }^{3}$, Angela P Mattos ${ }^{3}$, Danile L Barreto ${ }^{3}$, Lisa A Houghton ${ }^{1}$, \\ lan M Morison ${ }^{2}$, Sheila M Williams ${ }^{4}$ and Rosalind S Gibson ${ }^{1, *}$ \\ ${ }^{1}$ Department of Human Nutrition, University of Otago, PO Box 56, Dunedin, New Zealand: ${ }^{2}$ Department of \\ Pathology, University of Otago, Dunedin, New Zealand: ${ }^{3}$ Hospital Universitário Professor Edgard Santos, \\ Fima Lifshitz Research Unit, Salvador, Bahia, Brazil: ${ }^{4}$ Department of Preventive and Social Medicine, \\ University of Otago, Dunedin, New Zealand
}

Submitted 27 November 2012: Final revision received 23 June 2013: Accepted 25 July 2013: First published online 5 September 2013

\begin{abstract}
Objective: To examine the micronutrient status of disadvantaged pre-schoolers from Northeast Brazil, following the introduction of pro-poor policies, by assessing the prevalence of anaemia and micronutrient deficiencies and the role of sociodemographic factors, genetic $\mathrm{Hb}$ disorders and parasitic infections.

Design: In a cross-sectional study, data on sociodemographic status, health, growth, genetic $\mathrm{Hb}$ disorders, parasites and nutrient supply from day-care meals were obtained. Fasting blood samples were collected and analysed for $\mathrm{Hb}$, serum ferritin, transferrin receptor, folate, vitamin $\mathrm{B}_{12}$, retinol, $\mathrm{Zn}$ and $\mathrm{Se}$.

Setting: Seven philanthropic day-care centres serving urban slums in Salvador, Northeast Brazil.

Subjects: Pre-schoolers aged 3-6 years from disadvantaged households.

Results: Of the 376 sampled children, $94 \%$ were of black or mixed race; $33 \%$ and $29 \%$ had at least one genetic $\mathrm{Hb}$ disorder and intestinal parasite, respectively. Stunting and underweight were $\leq 5 \% ; 14 \%$ were overweight. Day-care centres supplied micronutrient-dense meals and snacks each weekday. Less than $10 \%$ of pre-schoolers had anaemia and micronutrient deficiencies. Predictors $(P<0 \cdot 05)$ of $\mathrm{Hb}$ were $\alpha^{3 \cdot 7}$ thalassaemia, Se and retinol (but not ferritin). Micronutrient predictors $(P<0 \cdot 05)$ were: elevated $\alpha_{1}$-glycoprotein for ferritin, Hb AS and BMI $Z$-score $>1$ for transferrin receptor, $\mathrm{Zn}$ and elevated $\alpha_{1}$-glycoprotein for retinol, sex and helminths for Se, helminths for vitamin $\mathrm{B}_{12}$, and Giardia intestinalis infection for serum folate.

Conclusions: Impaired growth, anaemia and micronutrient deficiencies were uncommon among these disadvantaged pre-schoolers attending day care. A range of interventions including provision of micronutrient-dense, fortified day-care meals, deworming and vitamin A supplementation likely contributed to improved micronutrient status, suggesting expanded coverage of these programmes.
\end{abstract}

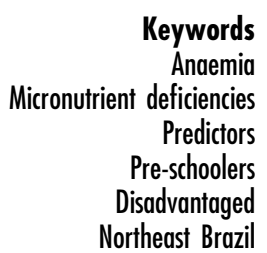

Many young children living in urban poverty today are vulnerable to malnutrition ${ }^{(1)}$. In Brazil, the Northeast (NE) region is the poorest in the country and where young children living in low-income urban slums are at increased risk of anaemia, micronutrient deficiencies and morbidity ${ }^{(2-4)}$. Together, these deleterious effects can have a long-lasting adverse impact on the cognitive and developmental potential of young children ${ }^{(5)}$.

Numerous diet and host-related factors may contribute to micronutrient malnutrition among urban slum preschoolers in NE Brazil. Their staple diets are based on cereals and legumes, and are devoid of expensive micronutrient-dense animal-source foods. Thus, the adequacy of key essential micronutrients such as bioavailable $\mathrm{Fe}$ and $\mathrm{Zn}$, preformed vitamin $\mathrm{A}$ and vitamin $\mathrm{B}_{12}$ may be compromised by low intakes and/or poor bioavailability from these plant-based diets ${ }^{(6)}$. In urban slum settings, the water supply and sanitation are poor ${ }^{(2)}$, so intestinal parasitic infections are often widespread ${ }^{(7)}$. Such infections can exacerbate poor micronutrient bioavailability by increasing permeability and reducing transit time in the intestine ${ }^{(8)}$. Furthermore, in Salvador, 
NE Brazil, $80 \%$ of the population is of West African descent ${ }^{(9)}$. Hence, some disadvantaged pre-schoolers in Salvador are likely to be at risk for genetic Hb disorders, particularly thalassaemias and sickle cell disease ${ }^{(10)}$, which can be associated with anaemia and Zn deficiency, respectively ${ }^{(11,12)}$.

Over recent decades, Brazil has implemented several key pro-poor policies to improve the micronutrient status, health, physical and cognitive development of urban preschoolers living in low-income environments. Policies include supplementation of young children with vitamin $\mathrm{A}$ and $\mathrm{Fe}^{(13)}$, mandatory fortification of wheat and corn flour with Fe and folic acid ${ }^{(13)}$, implementation of sewage and sanitation programmes ${ }^{(7)}$, and promotion of day-care facilities for the care and education of pre-schoolers ${ }^{(14)}$.

Nevertheless, there have been few comprehensive studies that have examined the micronutrient status of disadvantaged urban pre-schoolers attending day care in NE Brazil since the implementation of these policies. Consequently, little is known about the prevalence of micronutrient deficiencies among children in these settings today. In earlier reports, we have examined the growth, intestinal parasitic infections and adequacy of the nutrient supply from day-care meals in a group of pre-schoolers living in urban slums in Salvador, NE Brazil $^{(15,16)}$. Here, we extend the research by investigating the prevalence of anaemia and micronutrient deficiencies in these same children and exploring the major predictors of $\mathrm{Hb}$ and micronutrient biomarkers.

\section{Methods}

\section{Study sites and participants}

The present cross-sectional study was conducted between August and November 2010 in Salvador, in the state of Bahia, NE Brazil. Seven philanthropic pre-school day-care centres within the city centre and peri-urban areas participated, as described earlier ${ }^{(15)}$. These day-care centres were selected based on the criteria that all the children in attendance were from poor communities and participated full-time (i.e. 07.30-17.00 hours). The service provided was without charge and provided five meals per day, with an on-site dietitian.

The children ( $n$ 376) enrolled in the day-care centres (maximum class size of twenty-five children) were from low-income families and attended day care five days per week, except holidays, until school age. The day-care centres supplied filtered drinking water and the majority of the weekday food intake for the children, and provided flush toilets, hand basins and shower facilities. Inclusion criteria for the study were apparently healthy children enrolled in the day-care classes for 3- and 4-yearolds in the 2010 school year (February to December). The study protocol was approved by the Human Ethics Committees of the Federal University of Bahia, Salvador and the University of Otago, New Zealand. Informed written permission to participate in the study was given by the parents or primary guardians of the children.

\section{Questionnaire and assessment of children's growth, parasite status and day-care meals}

Data on sociodemographic status and health of the participants were collected via a culturally appropriate structured questionnaire, administered by trained research assistants. Methodological details are provided elsewhere ${ }^{(15)}$. Sociodemographic data were used to calculate an overall socio-economic status (SES) score for each participant based on a model designed to assess the poverty level of Brazilian families in low socio-economic urban populations ${ }^{(17)}$. Briefly, points were assigned for family and housing size and structure, parental education and occupation, marital status, ownership of house and household assets, toilet and sewage facilities, type of drinking water, availability of electricity and susceptibility of the house to flooding during heavy rain, and used to calculate two SES categories: extremely low and low SES, based on scores $\leq 34$ and $\geq 35$, respectively.

Health status variables of the child supplied by maternal report included coffee intake within the past $24 \mathrm{~h}$, smoking in the home and history of asthma in the mother or siblings. The mother also reported on the use of $\mathrm{Fe}$ supplements and deworming treatment within the past 6 months, whereas details of vitamin A supplementation was obtained from the child's health card. Ethnicity of the child was determined by skin colour, hair and facial characteristics, which were recorded by the research assistants, as performed in the national census ${ }^{(9)}$.

Weight and height measurements were taken with children wearing light clothes and no shoes using standardized techniques and calibrated equipment ${ }^{(18)}$. Standardized Z-scores for height-for-age (HAZ), weightfor-age (WAZ), weight-for-height (WHZ) and BMI (BMIZ) were calculated using the WHO 2006/2007 growth reference data ${ }^{(18,19)}$. Overweight and obesity in the children was defined as BMIZ $>1$ to $\leq 2$ and BMIZ $>2$, respectively.

Of the pre-schoolers, $86 \%(325 / 376)$ provided a stool sample which was examined by microscopy for helminths and protozoan intestinal parasites. Positive samples for Giardia intestinalis were identified by an enzyme immunoassay. Major food sources and adequacy of the micronutrient supply from twenty daily day-care menus was evaluated by procedures described earlier ${ }^{(16)}$.

\section{Biochemical assessment}

Morning fasting peripheral venepuncture blood samples were obtained with participants in a sitting position, after applying a topical local vasodilator anaesthetic (amethocaine; Ametop ${ }^{\mathrm{TM}}$ ) to minimize any discomfort. Blood was drawn into a trace-element-free evacuated tube (Becton Dickinson, Franklin Lakes, NJ, USA) for the micronutrient and infection biomarkers and into a paediatric evacuated tube containing EDTA (Becton Dickinson) for a complete 
blood count and for testing for genetic Hb disorders. All blood samples were refrigerated immediately following collection $^{(20)}$, protected from UV light, and the serum separated within $2 \mathrm{~h}$ using trace-element-free techniques. Aliquots of serum and washed red blood cells were frozen within $10 \mathrm{~min}$, initially at $-30^{\circ} \mathrm{C}$ and later at $-70^{\circ} \mathrm{C}$. An aliquot of EDTA-anticoagulated whole blood was haemolysed by a 1:10 dilution in 1\% ascorbic acid solution $(\mathrm{w} / \mathrm{w})$ and frozen for erythrocyte folate analysis ${ }^{(21)}$. Frozen samples were shipped on dry ice to the University of Otago, New Zealand for analysis.

Serum ferritin was determined on an Elecsys 2010 autoanalyser (Roche, New Zealand; $\mathrm{CV}=3 \%$ ) using a Ferritin Elecsys reagent kit (Roche Diagnostics GmbH, Mannheim Germany) and soluble transferrin receptor (sTfR) via an enzyme immunoassay (Ramco Laboratories Inc., Houston, TX, USA; CV $=7 \%$ ). Serum $\mathrm{Zn}$ was analysed by flame atomic absorption spectrophotometry (ContrAA 700; Analytik Jena AG, Jena, Germany; $\mathrm{CV}=5 \%)^{(22)}$ and serum Se by electrothermal atomic absorption spectrophotometry (AA-800, Perkin Elmer 2690; Ebos Group Ltd, Auckland, New Zealand; $\mathrm{CV}=7 \%)^{(23)}$. Serum retinol was analysed by $\mathrm{HPLC}^{(24)}(\mathrm{CV}=2 \%)$ and serum vitamin $\mathrm{B}_{12}$ by an electrochemiluminescence immunoassay $(\mathrm{CV}=4$ \%) using a Vitamin $\mathrm{B}_{12}$ Elecsys reagent kit (Roche Diagnostics $\mathrm{GmbH}$ ) on an Elecsys 2010 auto-analyser (Roche, New Zealand). Serum and whole-blood folate concentrations were measured by microbiological assay ${ }^{(25)}$ in ninety-six-well microtitre plates using chloramphenicolresistant cryopreserved Lactobacillus rhamnosus (ATCC 27773; American Type Culture Collection, Manassa, VA, USA) and 5-methyltetrahydrofolate as the calibrator (Merck \& Cie, Schaffhausen, Switzerland; CV $=14 \%$ ). Erythrocyte folate concentrations were calculated from whole blood values by using individual packed cell volumes and correction for serum folate concentration. Serum C-reactive protein (CRP) and $\alpha_{1}$-glycoprotein (AGP) concentrations were assayed by immunoturbidimetry (Roche Diagnostics $\mathrm{GmbH}$ ) on a Cobas Mira II auto-analyser ( $\mathrm{CV}=10 \%$ and $3 \%$, respectively). The precision of the biochemical assays was checked using a pooled serum sample and their accuracy established using certified reference materials or appropriate manufacturers' controls; values fell within the certified ranges.

The complete blood count was determined using an automatic electronic analyser (Coulter LH 750 Hematology Analyzer; Beckman Coulter Inc., São Paulo, Brazil) in the Professor Edgar Santos Hospital haematology laboratory, Salvador. Haemoglobinopathies were detected by alkaline and acid $\mathrm{Hb}$ electrophoresis analysis (Sebia Hydrasys Electrophoresis Analyzer; Sebia Inc., Norcross, GA, USA), which separated normal haemoglobins (A, $A_{2}$ and $\mathrm{F}$ ) and detected major $\mathrm{Hb}$ variants, including the heterozygous variant of $\mathrm{Hb} \mathrm{S}(\mathrm{Hb} \mathrm{AS})$ and $\mathrm{Hb} \mathrm{C}(\mathrm{Hb} \mathrm{AC})$. The presence of $\alpha^{3 \cdot 7}$ thalassaemia was determined by using a multiplex PCR reaction on extracted $\mathrm{DNA}^{(26)}$. Positive $\mathrm{Hb}$ and DNA controls were used for the electrophoresis analysis and PCR reactions, respectively. A negative control confirmed the absence of contamination for the PCR results, as described elsewhere ${ }^{(27)}$.

Anaemia and other haematological disturbances were defined using the following interpretive criteria: $\mathrm{Hb}$ $<110 \mathrm{~g} / 1$ and $<115 \mathrm{~g} / 1$ for children aged $<5$ years and $\geq 5$ years, respectively ${ }^{(28)}$; mean cell volume (MCV) $<73 \mathrm{fl}$ and $<74 \mathrm{fl}$ for children aged $<5$ years and $\geq 5$ years, respectively ${ }^{(28)}$; and red cell distribution width (RDW) $>14 \%{ }^{(29)}$. For storage Fe depletion, serum ferritin was defined as $<12 \mu \mathrm{g} / 1$ and $<15 \mu \mathrm{g} / 1$ for children aged $<5$ years and $\geq 5$ years, respectively ${ }^{(28)}$. Tissue Fe deficiency was defined as sTfR $>8.5 \mathrm{mg} / \mathrm{l}^{(30)}$. $\mathrm{Hb}$ AS and $\mathrm{Hb} \mathrm{AC}$, and $\alpha^{3 \cdot 7}$ thalassaemia, homozygous or heterozygous, were identified as present or absent.

Interpretive criteria to define micronutrient deficiencies were: $\operatorname{serum~} \mathrm{Zn}<9.9 \mu \mathrm{mol} / \mathrm{l}^{(31)}$, Se $\leq 0.82 \mu \mathrm{mol} / \mathrm{l}^{(32)}$, retinol $<0 \cdot 70 \mu \mathrm{mol} / \mathrm{l}^{(33)}$ and vitamin $\mathrm{B}_{12}<150 \mathrm{pmol} / \mathrm{l}^{(34)}$. Marginal vitamin A status was defined as serum retinol $\geq 0.7$ but $<1.05 \mu \mathrm{mol} / \mathrm{l}^{(35)}$. Low serum folate concentration was defined as $<6.8 \mathrm{nmol} / 1$ and low erythrocyte folate as $<317 \mathrm{nmol} / \mathrm{l}^{(36)}$. Acute and chronic inflammation were assessed by serum CRP $>5 \mathrm{mg} / \mathrm{l}^{(37)}$ and AGP $>1 \cdot 0 \mathrm{~g} / \mathrm{l}^{(38)}$, respectively.

\section{Statistical analysis}

Selected characteristics of the children and households, and prevalence of intestinal parasites and genetic $\mathrm{Hb}$ disorders are presented as percentages. Means and standard deviations were calculated for haematology and micronutrient biomarkers, and adjusted where necessary for inflammation (i.e. ferritin and retinol) ${ }^{(39,40)}$. Associations between elevated AGP concentrations $(>1 \mathrm{~g} / \mathrm{l})$ and BMIZ $>1$ and between the presence of genetic $\mathrm{Hb}$ disorders and ethnicity were investigated using Fisher's exact test. AGP was used as a dichotomized variable because the precision of the assay precluded using the data as a continuous variable. Data were log-transformed if the variable had a strongly skewed distribution (e.g. ferritin, sTfR, retinol and serum folate). Multiple regression models included variables if associations using univariate regression analysis were $P<0 \cdot 2$. The sandwich estimator was used to obtain robust standard errors, to account for the sampling procedure. Statistical analyses were carried out using the statistical software package STATA version 11.

\section{Results}

\section{Sociodemographic, bealth, growth and parasite status}

Of the 438 eligible children, 378 (86\%) were recruited. Reasons for non-participation included children on the roll who had moved or were moving during the study, children who were chronically ill and not in regular 
day-care attendance, and parental refusal. Mean age of the children was $4 \cdot 2(\mathrm{SD} 0 \cdot 61)$ years and $52 \%$ were boys (Table 1). Of the households, 48.4\% (182/376) were classified as extremely low SES and $51 \cdot 6 \%$ as low SES. Most of the pre-schoolers were black $(42 \cdot 2 \%)$ or mixed

Table 1 Sociodemographic, growth, health, parasite status, genetic $\mathrm{Hb}$ disorders and elevated biomarkers of inflammation among pre-schoolers aged 3-6 years from disadvantaged households, Salvador, Northeast Brazil, August-November 2010

\begin{tabular}{|c|c|c|}
\hline & $n$ & $\%$ \\
\hline Age (years) & 376 & \\
\hline Mean & \\
\hline SD & \multicolumn{2}{|c|}{0.61} \\
\hline Sex (male) & $196 / 376$ & $52 \cdot 1$ \\
\hline SES (extremely low) & $182 / 376$ & $48 \cdot 4$ \\
\hline \multicolumn{3}{|l|}{ Ethnicity } \\
\hline Black & $154 / 365$ & $42 \cdot 2$ \\
\hline Mixed (i.e. brown) & $189 / 365$ & $51 \cdot 8$ \\
\hline White & 22/365 & $6 \cdot 0$ \\
\hline \multicolumn{3}{|l|}{ Growth measurements } \\
\hline Stunted $(H A Z<-2)$ & $10 / 364$ & $2 \cdot 8$ \\
\hline Underweight $(W A Z<-2)$ & $2 / 364$ & 0.6 \\
\hline Overweight (BMIZ $>1$ to $\leq 2)$ & $40 / 364$ & $11 \cdot 0$ \\
\hline Obese $(\mathrm{BMIZ}>2)$ & $12 / 364$ & $3 \cdot 3$ \\
\hline \multicolumn{3}{|l|}{ Smoking } \\
\hline Mother smoking in the house & $47 / 376$ & $12 \cdot 5$ \\
\hline Adult smoking in the house & $89 / 376$ & $23 \cdot 7$ \\
\hline History of asthma in mother or sibling & $68 / 376$ & $18 \cdot 1$ \\
\hline Coffee intake within past $24 \mathrm{~h}$ & $149 / 376$ & $39 \cdot 6$ \\
\hline Fe syrup within 6 months & $70 / 376$ & $18 \cdot 6$ \\
\hline Vitamin A supplementation ever received & $200 / 376$ & $53 \cdot 2$ \\
\hline Deworming treatment within 6 months & 192/376 & $51 \cdot 1$ \\
\hline Parasite present & $95 / 325$ & $29 \cdot 2$ \\
\hline Helminths & $58 / 325$ & $17 \cdot 8$ \\
\hline Trichuris trichiura & $39 / 325$ & $12 \cdot 0$ \\
\hline Ascaris lumbricoides & $34 / 325$ & $10 \cdot 5$ \\
\hline Hookworm & $3 / 325$ & 0.9 \\
\hline Giardia intestinalis & $42 / 325$ & $12 \cdot 9$ \\
\hline \multirow{2}{*}{\multicolumn{3}{|c|}{ Haemoglobinopathies }} \\
\hline & & \\
\hline $\mathrm{Hb}$ AS & $20 / 358$ & $5 \cdot 6$ \\
\hline $\mathrm{Hb} \mathrm{AC}$ & $9 / 358$ & $2 \cdot 5$ \\
\hline \multicolumn{3}{|l|}{$\alpha^{3.7}$ Thalassaemia } \\
\hline Heterozygous & $70 / 306$ & $22 \cdot 9$ \\
\hline Homozygous & $6 / 306$ & $2 \cdot 0$ \\
\hline$A G P>1.0 \mathrm{~g} / \mathrm{l}$ & $112 / 358$ & $31 \cdot 3$ \\
\hline $\mathrm{CRP}>5 \mathrm{mg} / \mathrm{l}$ & $46 / 358$ & $12 \cdot 9$ \\
\hline
\end{tabular}

SES, socio-economic status; HAZ, height-for age Z-score; WAZ, weight-for-age $Z$-score; BMIZ, BMI Z-score; AGP, $\alpha_{1}$-glycoprotein; CRP, C-reactive protein. race (i.e. brown; $51 \cdot 8 \%$ ); only $6.0 \%$ were white. More than $50 \%$ had received vitamin A supplements and deworming treatment, but less than $20 \%$ had reportedly been supplemented with Fe.

Prevalence of stunting and underweight was low $(\leq 5 \%)$, whereas that of overweight and obesity was $11 \cdot 0 \%$ and $3 \cdot 3 \%$, respectively (Table 1 ). Stool samples were provided by $86 \%$ (325/376) of the pre-schoolers, of whom nearly $30 \%$ were infected with at least one intestinal parasite (Table 1). No significant differences in age, sex, sociodemographic status and deworming treatment were found between participants who provided a stool sample and those participants who did not ( $n$ 51), except for the use of vitamin A supplements. Daily supply of almost all micronutrients from the day-care meals appeared adequate except for vitamin A, where risk of adequacy was $\leq 50 \%$, also reported earlier ${ }^{(16)}$. Intake of animal-source foods from the day-care meals was $80 \mathrm{~g} / \mathrm{d}$.

\section{Genetic Hb disorders, biomarkers of infection and baematology}

Almost a third of the pre-schoolers had at least one genetic $\mathrm{Hb}$ disorder, of which the most prevalent was heterozygous $\alpha^{3 \cdot 7}$ thalassaemia (23\%). Prevalence of $\mathrm{Hb}$ $\mathrm{AS}$ and $\mathrm{Hb}$ AC was low (Table 1). Four children had both a haemoglobinopathy and $\alpha^{3 \cdot 7}$ thalassaemia. Prevalence of genetic $\mathrm{Hb}$ disorders was independent of ethnicity. $\mathrm{Hb}$ AS tended to be higher in the black children $(60 \%, 12 / 20)$ compared with those of mixed race (i.e. $30 \%, 6 / 20$ ) or white $(10 \%, 2 / 20)$, although the difference was not significant $(P=0 \cdot 084)$. Only $13 \%$ had elevated CRP, although nearly a third had elevated AGP (Table 1). Overweight (i.e. BMIZ $>1$ ) was more prevalent among those with AGP $>1 \mathrm{~g} / 1$ compared to those with AGP $\leq 1 \mathrm{~g} / 1$ (i.e. $49 \%, 24 / 49$ v. 29\%, 87/303; $P=0 \cdot 007$ ).

Significant differences existed across the $\mathrm{Hb}$ variants for $\mathrm{Hb}, \mathrm{MCV}$ and RDW $(P<0 \cdot 001)$, with $\mathrm{Hb}$ AA children having greater mean $\mathrm{Hb}$ and $\mathrm{MCV}$, and lower RDW, compared with children with $\mathrm{Hb}$ AS and $\mathrm{Hb} \mathrm{AC}$ and/or $\alpha^{3 \cdot 7}$ thalassaemia. There were no significant differences across the groups for serum ferritin and sTfR (Table 2).

Table 2 Mean values (and standard deviation) for haematological variables and iron biomarkers for normal $\mathrm{Hb}$ type (Hb AA) and the four major abnormal $\mathrm{Hb}$ variants among pre-schoolers aged 3-6 years from disadvantaged households, Salvador, Northeast Brazil, August-November 2010

\begin{tabular}{|c|c|c|c|c|c|c|c|c|c|c|c|}
\hline & \multicolumn{2}{|c|}{$\mathrm{Hb}$ AA $(n 210)$} & \multicolumn{2}{|c|}{$\mathrm{Hb}$ AS ( $n$ 20) } & \multicolumn{2}{|c|}{$\mathrm{Hb} \mathrm{AC}(n 9)$} & \multicolumn{2}{|c|}{$\begin{array}{c}\alpha^{3 \cdot 7} \text { Thalassaemia } \\
\text { heterozygoust }(n 66)\end{array}$} & \multicolumn{2}{|c|}{$\begin{array}{l}\alpha^{3 \cdot 7} \text { Thalassaemia } \\
\text { homozygous }(n 6)\end{array}$} & \multirow[b]{2}{*}{$P$} \\
\hline & Mean & SD & Mean & SD & Mean & SD & Mean & SD & Mean & SD & \\
\hline $\mathrm{Hb}(g / l)$ & $124 \cdot 1$ & $7 \cdot 1$ & $122 \cdot 5$ & $6 \cdot 6$ & $121 \cdot 9$ & $13 \cdot 5$ & $119 \cdot 4$ & $6 \cdot 5$ & $111 \cdot 8$ & $4 \cdot 4$ & $<0.001$ \\
\hline MCV (fl) & $80 \cdot 7$ & $3 \cdot 2$ & $79 \cdot 4$ & $4 \cdot 1$ & $72 \cdot 9$ & $5 \cdot 1$ & $75 \cdot 4$ & $3 \cdot 4$ & $63 \cdot 8$ & $2 \cdot 4$ & $<0.001$ \\
\hline RDW (\%) & 13.9 & $1 \cdot 0$ & $13 \cdot 9$ & $2 \cdot 6$ & $15 \cdot 2$ & 0.9 & $14 \cdot 4$ & 1.5 & $16 \cdot 4$ & $1 \cdot 1$ & $<0.001$ \\
\hline Ferritin $\ddagger(\mu \mathrm{g} / \mathrm{l})$ & $41 \cdot 3$ & $19 \cdot 9$ & $43 \cdot 6$ & $18 \cdot 5$ & $34 \cdot 1$ & $10 \cdot 2$ & $43 \cdot 6$ & $17 \cdot 2$ & $38 \cdot 3$ & $14 \cdot 4$ & 0.084 \\
\hline sTfR (mg/l) & $7 \cdot 1$ & 1.5 & $8 \cdot 1$ & $2 \cdot 6$ & $7 \cdot 8$ & 1.5 & $7 \cdot 4$ & $1 \cdot 7$ & $7 \cdot 2$ & $1 \cdot 4$ & 0.250 \\
\hline
\end{tabular}

MCV, mean cell volume; RDW, red cell distribution width; sTfR, soluble transferrin receptor.

tParticipants with concomitant $\mathrm{Hb}$ AS or $\mathrm{Hb}$ AC were excluded $(n 4)$.

$\ddagger$ Adjusted for infection ${ }^{(39)}$. 
Table 3 Prevalence (\% and $95 \%$ confidence interval) of anaemia and micronutrient deficiencies, and mean values (and standard deviation) of specific micronutrient biomarkers, including adjusted mean values for those impacted by infection, among pre-schoolers aged 3-6 years from disadvantaged households, Salvador, Northeast Brazil, August-November 2010

\begin{tabular}{|c|c|c|c|}
\hline & $n$ & $\%$ or Mean & $95 \% \mathrm{Cl}$ or $\mathrm{SD}$ \\
\hline \multicolumn{4}{|l|}{$\mathrm{Hb}$} \\
\hline$<5$ years of age $(<110 \mathrm{~g} / \mathrm{l})$ & $11 / 319$ & $3 \cdot 4$ & $1 \cdot 7,6 \cdot 1$ \\
\hline$\geq 5$ years of age $(<115 \mathrm{~g} / \mathrm{l})$ & $3 / 40$ & $7 \cdot 5$ & $1 \cdot 5,21 \cdot 9$ \\
\hline \multicolumn{4}{|l|}{ Serum ferritint } \\
\hline$<5$ years of age $(<12 \mu \mathrm{g} / \mathrm{l})$ & $6 / 318$ & $1 \cdot 9$ & $0 \cdot 7,4 \cdot 1$ \\
\hline$\geq 5$ years of age $(<15 \mu \mathrm{g} / \mathrm{l})$ & $1 / 40$ & $2 \cdot 5$ & $0 \cdot 1,13 \cdot 9$ \\
\hline Serum sTfR $>8.5 \mathrm{mg} / \mathrm{l}$ & $54 / 358$ & $15 \cdot 1$ & $11 \cdot 5,19 \cdot 2$ \\
\hline Serum Zn $(\mu \mathrm{mol} / \mathrm{l})$ & 358 & $12 \cdot 8$ & $1 \cdot 8$ \\
\hline Low serum Zn $(<9.9 \mu \mathrm{mol} / \mathrm{l})$ & $13 / 358$ & $3 \cdot 6$ & $1 \cdot 9,6 \cdot 1$ \\
\hline Serum retinol $(\mu \mathrm{mol} / \mathrm{l})$ & 358 & $1 \cdot 09 \ddagger$ & 0.24 \\
\hline Low serum retinolł $(<0.7 \mu \mathrm{mol} / \mathrm{l})$ & $10 / 358$ & $2 \cdot 8$ & $1 \cdot 3,5 \cdot 1$ \\
\hline Marginal retinol deficiency $(0 \cdot 7-1.05 \mu \mathrm{mol} / \mathrm{l})$ & $158 / 358$ & $44 \cdot 1$ & $38 \cdot 9,49 \cdot 4$ \\
\hline Serum Se $(\mu \mathrm{mol} / \mathrm{l})$ & 358 & 0.99 & 0.14 \\
\hline Low serum Se $(\leq 0.82 \mu \mathrm{mol} / \mathrm{l})$ & $34 / 358$ & $9 \cdot 5$ & $6 \cdot 7,13 \cdot 0$ \\
\hline Serum vitamin $B_{12}(p m o l / /)$ & 357 & 649 & 224 \\
\hline Low serum vitamin $B_{12}(<148 \mathrm{pmol} / \mathrm{l})$ & $1 / 357$ & 0.3 & $0.01,1 \cdot 7$ \\
\hline Marginal vitamin $\mathrm{B}_{12}$ deficiency $(148-221 \mathrm{pmol} / \mathrm{l})$ & $5 / 357$ & $1 \cdot 4$ & $0.5,3 \cdot 3$ \\
\hline Serum folate $(\mathrm{nmol} / \mathrm{l})$ & 355 & 51 & 21 \\
\hline Low serum folate $(<6 \cdot 8 \mathrm{nmol} / \mathrm{l})$ & 0/355 & 0 & $0,1 \cdot 0$ \\
\hline Erythrocyte folate $(\mathrm{nmol} / \mathrm{l})$ & 355 & 1253 & 390 \\
\hline Low erythrocyte folate $(<317 \mathrm{nmol} / \mathrm{l})$ & $0 / 355$ & 0 & $0,1 \cdot 0$ \\
\hline
\end{tabular}

STfR, soluble transferrin receptor.

tAdjusted for infection ${ }^{(39)}$

$\ddagger$ Adjusted for infection ${ }^{(38)}$.

\section{Anaemia and micronutrient deficiencies}

Mean concentrations of $\mathrm{Hb}$ and the micronutrient biomarkers and the prevalence of anaemia and micronutrient deficiencies are shown in Table 3. Prevalence of anaemia and micronutrient deficiencies was $<10 \%$, and ranged from $0 \%$ for folate to $9.5 \%$ for Se (Table 3); $13 \%$ (46/358) had at least one micronutrient deficiency. The prevalence of anaemia was higher among children with at least one $\mathrm{Hb}$ disorder than among those without $\mathrm{Hb}$ disorders (i.e. $69 \%, 9 / 13 v .31 \%, 4 / 13 ; P=0.006)$. Of the few children with depleted Fe stores ( $2 \%, 7 / 358)$, only one child had an $\mathrm{Hb}$ disorder. However, 15\% (54/358) had elevated sTfR indicative of tissue Fe deficiency, of whom $30 \%$ (16/54) had an abnormal Hb variant.

\section{Predictors of $\mathrm{Hb}$ and micronutrient biomarkers}

Table 4 shows the significant predictors of $\mathrm{Hb}$ and biomarkers of Fe status. Both homozygous and heterozygous $\alpha^{3 \cdot 7}$ thalassaemia variants were negative determinants of $\mathrm{Hb}(P \leq 0 \cdot 001)$, whereas Se and retinol were positive determinants of $\mathrm{Hb}$; serum ferritin was not a significant determinant of $\mathrm{Hb}$. BMIZ $>1$ and $\mathrm{Hb}$ AS were positive determinants of sTfR but had no effect on ferritin. Elevated AGP was a positive determinant of ferritin.

In contrast, AGP was a negative determinant of retinol, whereas Zn was a positive predictor of retinol (Table 5). Being male was positively associated with Se, whereas helminths were a negative predictor of Se and vitamin $\mathrm{B}_{12}$. G. intestinalis was a positive predictor of serum but not erythrocyte folate. The associations between either
$\mathrm{Hb}$ or micronutrient biomarkers and age, sex (with the exception of Se), ethnicity, supplementation with Fe or vitamin A, deworming treatment, smoking in the home, family history of asthma and recent coffee intake were not statistically significant.

\section{Discussion}

Our findings highlight the low prevalence of anaemia and micronutrient deficiencies in these disadvantaged preschoolers attending philanthropic day-care centres. To our knowledge, these data are the first in Brazil to examine six micronutrient biomarkers in this age group concurrently and to investigate the complex interrelationships between $\mathrm{Hb}$, micronutrient status, parasitic infections and genetic Hb disorders.

The low prevalence of anaemia reported here (i.e. $<4 \%$ ) was unexpected. Earlier studies of urban preschoolers in NE Brazil $^{(41)}$, including Salvador ${ }^{(3)}$, have reported much greater anaemia rates, sometimes as high as $40 \%{ }^{(42)}$. Several factors may account for our unexpected finding. The most frequent genetic $\mathrm{Hb}$ disorder among these pre-schoolers was heterozygous $\alpha^{3 \cdot 7}$ thalassaemia (23\%), which, unlike the homozygous variant, is relatively benign and is not always associated with anaemia.

Moreover, review of the day-care meals indicated that the supply of all the micronutrients with a major role in the maintenance of normal haematopoietic function (i.e. Fe, folate and vitamin $\mathrm{B}_{12}$ ), with the exception of 
Table 4 Predictors of $\mathrm{Hb}$ and two biomarkers of iron status based on both univariate and multiple regression models, as shown by $\beta$ coefficient (and $95 \%$ confidence interval), among pre-schoolers aged 3-6 years from disadvantaged households, Salvador, Northeast Brazil, August-November 2010

\begin{tabular}{|c|c|c|c|c|}
\hline & Univariate $\beta$ & Multivariate $\beta$ & $95 \% \mathrm{Cl}$ & $P$ \\
\hline \multicolumn{5}{|l|}{$\mathrm{Hbt}$} \\
\hline$\alpha^{3 \cdot 7}$ Thalassaemia homozygous & $-12 \cdot 29^{*}$ & $-12 \cdot 19$ & $-14 \cdot 78,-9 \cdot 60$ & $<0.001$ \\
\hline $\begin{array}{l}\alpha^{3 \cdot 7} \text { Thalassaemia heterozygous } \\
\mathrm{Hb} \text { AS }\end{array}$ & $\begin{array}{l}-4 \cdot 84^{*} \\
-0 \cdot 44\end{array}$ & $-5 \cdot 28$ & $-7 \cdot 44,-3 \cdot 11$ & 0.001 \\
\hline $\begin{array}{l}\mathrm{HB} A \mathrm{~A} \\
\mathrm{Hb} \mathrm{AC}\end{array}$ & $\begin{array}{l}-0.44 \\
-1.00\end{array}$ & & & \\
\hline $\mathrm{Se}$ & $11 \cdot 71^{*}$ & $11 \cdot 71$ & $6 \cdot 26,17 \cdot 17$ & 0.001 \\
\hline Retinol (log-transformed) & $7 \cdot 62^{*}$ & $5 \cdot 08$ & $0.65,9.51$ & 0.030 \\
\hline Ferritin (log-transformed) & $2 \cdot 11^{(*)}$ & $2 \cdot 35$ & $-0 \cdot 76,5 \cdot 46$ & $0 \cdot 117$ \\
\hline $\mathrm{Zn}$ & $0 \cdot 71^{*}$ & $0 \cdot 42$ & $-0.09,0.92$ & 0.092 \\
\hline $\mathrm{AGP}>1 \mathrm{~g} / \mathrm{l}$ & $0 \cdot 01^{(*)}$ & $0 \cdot 29$ & $-2 \cdot 09,2 \cdot 68$ & 0.779 \\
\hline \multicolumn{5}{|l|}{ Serum ferritin (log-transformed)‡ } \\
\hline Age & 0.03 & & & \\
\hline $\mathrm{BMIZ}>1$ & $0 \cdot 10^{*}$ & 0.04 & $-0.02,0.10$ & $0 \cdot 138$ \\
\hline$A G P>1 \mathrm{~g} / \mathrm{l}$ & $0 \cdot 31^{*}$ & 0.30 & $0 \cdot 16,0 \cdot 44$ & 0.001 \\
\hline $\mathrm{Hb}$ AS & 0.07 & & & \\
\hline $\mathrm{Hb} A C$ & $-0 \cdot 12$ & & & \\
\hline$\alpha^{3 \cdot 7}$ Thalassaemia heterozygous & 0.04 & & & \\
\hline$\alpha^{3 \cdot 7}$ Thalassaemia homozygous & -0.05 & & & \\
\hline \multicolumn{5}{|l|}{ Serum sTfR (log-transformed) $\S$} \\
\hline Age & $-0.04^{*}$ & -0.03 & $-0.06,0.01$ & 0.086 \\
\hline Sex & 0.04 & & & \\
\hline $\mathrm{BMIZ}>1$ & $0 \cdot 10^{*}$ & 0.09 & $0.00,0.17$ & 0.050 \\
\hline Helminths & $-0.06^{(*)}$ & -0.06 & $-0.14,0.03$ & $0 \cdot 163$ \\
\hline $\mathrm{Hb}$ AS & $0 \cdot 16^{*}$ & $0 \cdot 17$ & $0.04,0.31$ & 0.020 \\
\hline $\mathrm{Hb} \mathrm{AC}$ & 0.09 & & & \\
\hline$\alpha^{3 \cdot 7}$ Thalassaemia heterozygous & 0.03 & & & \\
\hline$\alpha^{3 \cdot 7}$ Thalassaemia homozygous & 0.01 & & & \\
\hline
\end{tabular}

AGP, $\alpha_{1}$-glycoprotein; BMIZ, BMI Z-score.

All variables with $P<0.2$ in the univariate analysis were included in the multivariate regression.

For all binary categorical variables, the reference was the absence of the condition specified.

${ }^{\star}{ }^{*} P<0.2$ based on univariate regression; ${ }^{\star} P<0.05$ based on univariate regression.

$+R^{2}$ for multivariate regression model $=0 \cdot 242$.

$\ddagger R^{2}$ for multivariate regression model $=0.098$.

$\S R^{2}$ for multivariate regression model $=0.083$.

vitamin A, met the requirements of the pre-schoolers. For example, animal-source foods provided in the day-care meals $(80 \mathrm{~g} / \mathrm{d})$, provision of legumes and use of fortified cereal flours in meal preparation ${ }^{(16)}$ and some supplementation sources of $\mathrm{Fe}$ and vitamin A (albeit minimal coverage $)^{(15)}$ contributed to the daily nutrient requirements in these children. Despite the seeming lack of impact of mandatory Fe fortification alone on anaemia in Brazilian pre-schoolers ${ }^{(43)}$, these multiple strategies were most likely responsible, at least in part, for the lower prevalences of anaemia and vitamin A deficiency reported here compared with earlier studies of pre-schoolers attending day-care centres in NE Brazil ${ }^{(41,44)}$.

Notwithstanding the apparently low prevalence of micronutrient deficiencies, there was some evidence of marginal vitamin A (45\%) and Se (9.5\%) status. The existence of suboptimal vitamin A status was attributed to an inadequate supply of vitamin A from day-care meals together with rather poor coverage of vitamin A supplementation (i.e. $50 \%$ ). Zn status may have also played a role in vitamin A status in view of the positive association between $\mathrm{Zn}$ and retinol observed here. This relationship is not unexpected; $\mathrm{Zn}$ has a role in the hepatic synthesis of retinol-binding protein, and thus in the transport and utilization of retinol, although in other studies where a similar relationship has been observed, the prevalence of Zn deficiency has been higher ${ }^{(45)}$.

Reasons for the suboptimal Se status are uncertain. It could be associated with low soil Se levels and thus low levels of Se in the major locally grown plant-based staples. However, we were unable to locate values for the concentrations of Se in locally grown foods, so the supply of Se from the day-care meals is unknown.

It is of interest that both serum retinol and Se each had independent and significant positive associations with $\mathrm{Hb}$ (Table 4). The positive relationship between retinol and $\mathrm{Hb}$ is attributed to the role of vitamin $\mathrm{A}$ in the mobilization of Fe from the spleen or liver into the circulation ${ }^{(46)}$, a mechanism that may account for the low prevalence of storage Fe depletion (i.e. $<3 \%$ ) reported here. There are several plausible mechanisms whereby Se status might impact on $\mathrm{Hb}$, including its affect on the activity of thioredoxin reductase, a selenoenzyme postulated to be implicated in the up-regulation of hepatic haem oxygenase- 1 involved in haem catabolism ${ }^{(47)}$. In addition, reduced activity of glutathione peroxidase, a selenoenzyme that may protect $\mathrm{Hb}$ against oxidation in red blood cells ${ }^{(48)}$, can result in increased inflammation and 
Table 5 Predictors of micronutrients based on both univariate and multiple regression models, as shown by $\beta$ coefficient (and 95\% confidence interval), among pre-schoolers aged 3-6 years from disadvantaged households, Salvador, Northeast Brazil, August-November 2010

\begin{tabular}{|c|c|c|c|c|}
\hline & Univariate $\beta$ & Multivariate $\beta$ & $95 \% \mathrm{Cl}$ & $P$ \\
\hline \multicolumn{5}{|l|}{ Serum retinol (log-transformed)† } \\
\hline Age & -0.01 & & & \\
\hline Sex (male) & $-0.04^{(*)}$ & -0.04 & $-0.09,0.01$ & 0.076 \\
\hline $\mathrm{Zn}$ & $0.02^{*}$ & 0.02 & $0.003,0.04$ & 0.031 \\
\hline$A G P>1 \mathrm{~g} / \mathrm{l}$ & $-0 \cdot 12^{*}$ & $-0 \cdot 12$ & $-0.17,-0.07$ & 0.001 \\
\hline Helminths & -0.08 & & & \\
\hline Giardia intestinalis & $-0.06^{(*)}$ & -0.06 & $-0.15,0.03$ & $0 \cdot 167$ \\
\hline Vitamin A supplementation & 0.00 & & & \\
\hline \multicolumn{5}{|l|}{ Serum Zn } \\
\hline Age & 0.03 & & & \\
\hline Sex (male) & 0.01 & & & \\
\hline $\mathrm{Se}$ & $1 \cdot 88^{(*)}$ & $1 \cdot 99$ & $-0 \cdot 38,4 \cdot 37$ & 0.088 \\
\hline$A G P>1 \mathrm{~g} / \mathrm{l}$ & $-0 \cdot 19$ & & & \\
\hline Helminths & $-0.61^{(*)}$ & -0.50 & $-1 \cdot 33,0 \cdot 32$ & $0 \cdot 190$ \\
\hline Giardia intestinalis & -0.27 & & & \\
\hline \multicolumn{5}{|l|}{ Serum Se $\S$} \\
\hline Age & 0.03 & & & \\
\hline Sex (male) & $0.04^{(*)}$ & 0.05 & $0.01,0.09$ & $0 \cdot 018$ \\
\hline$A G P>1 \mathrm{~g} / \mathrm{l}$ & $-0.03^{(*)}$ & -0.04 & $-0.08,0.01$ & $0 \cdot 080$ \\
\hline Helminths & $-0.05^{\star}$ & -0.06 & $-0.10,-0.03$ & 0.006 \\
\hline Giardia intestinalis & -0.01 & & & \\
\hline \multicolumn{5}{|l|}{ Serum vitamin $B_{12} \|$} \\
\hline Age & $-33 \cdot 70^{(*)}$ & -33.06 & $-67 \cdot 02,0 \cdot 90$ & 0.055 \\
\hline Sex (male) & $-62 \cdot 25^{(*)}$ & $-49 \cdot 44$ & $-144 \cdot 02,45 \cdot 14$ & $0 \cdot 256$ \\
\hline$A G P>1 \mathrm{~g} / \mathrm{l}$ & $38 \cdot 33$ & & & \\
\hline Helminths & $-116 \cdot 01^{*}$ & $-97 \cdot 63$ & $-188 \cdot 33,-6 \cdot 93$ & 0.038 \\
\hline Giardia intestinalis & $-70 \cdot 56^{*}$ & $-49 \cdot 12$ & $-102 \cdot 88,4 \cdot 64$ & 0.068 \\
\hline \multicolumn{5}{|l|}{ Serum folate (log-transformed) } \\
\hline Age & 0.02 & & & \\
\hline Sex (male) & $-0 \cdot 12^{(*)}$ & $-0 \cdot 12$ & $-0.26,0.02$ & 0.088 \\
\hline Helminths & 0.04 & & & \\
\hline Giardia intestinalis & $0 \cdot 14^{(*)}$ & $0 \cdot 14$ & $0.01,0.28$ & 0.041 \\
\hline
\end{tabular}

AGP, $\alpha_{1}$-glycoprotein.

All variables with $P<0.2$ in the univariate regression were included in the multivariate regression.

For all binary categorical variables, the reference was the absence of the condition specified.

${ }^{(\star)} P<0.2$ based on univariate regression; ${ }^{\star} P<0.05$ based on univariate regression.

$+R^{2}$ for multivariate regression model $=0 \cdot 111$.

$\ddagger R^{2}$ for multivariate regression model $=0.041$.

$\S R^{2}$ for multivariate regression model $=0.073$.

$\| R^{2}$ for multivariate regression model $=0.063$.

$\uparrow R^{2}$ for multivariate regression model $=0.036$.

oxidative stress. This inflammatory response may also be induced by intestinal parasites and may account for the independent and negative impact of helminths on Se concentrations.

During inflammation, pro-inflammatory cytokines such as IL-6 and leptin stimulate an increase in circulating hepcidin produced by both the liver and adipose tissue, which in turn down-regulates Fe absorption independent of $\mathrm{Fe}$ status, leading to functional $\mathrm{Fe}$ deficiency ${ }^{(49)}$. Chronic inflammation also accompanies overweight and obesity and thus may account for the observed positive relationship between overweight and sTfR (Table 4).

Parasitic infections are also known to play a role in the aetiology of anaemia. In the present study parasitic infections were not predictors of $\mathrm{Hb}$, but instead were associated with vitamin $B_{12}$ and folate status of the preschoolers. Their effect, however, although negative for vitamin $B_{12}$, was positive for folate status. The negative relationship between vitamin $B_{12}$ status and infection with helminths, and to a lesser extent G. intestinalis, is well recognized ${ }^{(50,51)}$. Such infections are not only associated with changes in small intestine morphology that lead to reductions in the absorptive surface ${ }^{(8)}$, but also with increased bacterial overgrowth that causes malabsorption, specifically of vitamin $\mathrm{B}_{12}{ }^{(51)}$. Risk of bacterial overgrowth is especially high for Brazilian pre-school children living in urban slum environments ${ }^{(52)}$, emphasizing the importance of the adequate supply of animalsource foods in the day-care meals.

The positive association between serum folate status and Giardia infection observed here was unexpected but is not implausible. Mandatory folate fortification of cereal flours may have created a folate-rich environment which provided optimal conditions for the adherence of Giardia trophozoites to the intestinal epithelium ${ }^{(53,54)}$. Alternatively, high levels of circulating unmetabolized folic acid from folate fortification of flour ${ }^{(55)}$ have been associated with decreased innate immune function ${ }^{(56)}$. This finding was 
attributed to reduced natural killer cell cytotoxicity, a mechanism responsible for targeting invading pathogens. However, to date these findings have been observed only in postmenopausal women and need to be replicated in other studies. Clearly, further research is warranted to confirm the positive association noted here between serum folate and Giardia infection, and establish the underlying biological mechanism.

Our findings are based on a cross-sectional study and hence preclude causal inferences from being made. Sampling was restricted to seven philanthropically funded day-care centres that provide a free service, so results may not apply to other day-care settings. Unfortunately, very limited data exist from the Salvador city registration on the number of philanthropic, public and private day-care centres for children of this age group. To our knowledge, the philanthropic day-care centres included here are unique to Salvador. The public government day care is also usually free of charge, but like the private day care, provides fewer meals (i.e. four and three, respectively) than the philanthropically funded day-care centres studied here. Furthermore, although we investigated several genetic $\mathrm{Hb}$ disorders, we were unable to measure all genetic factors, including glucose-6-phosphate dehydrogenase deficiency, which may have affected $\mathrm{Hb}$ and micronutrient levels, especially among the pre-schoolers of West African descent. Nevertheless, we did investigate $\mathrm{Hb}$, six micronutrients, micronutrient supply from daycare meals, acute and chronic inflammation, parasite and health status variables, which together provide a greater understanding of factors influencing $\mathrm{Hb}$ and micronutrient status in these disadvantaged pre-schoolers.

\section{Conclusions}

In conclusion, even though the pre-schoolers were living in urban slum settings, impaired growth and anaemia and micronutrient deficiencies were uncommon. These results are most likely a reflection of the provision of micronutrient-rich day-care meals fortified with $\mathrm{Fe}$ and folic acid, parasite control and vitamin A supplementation, and coverage of these programmes should be expanded. Nevertheless, the existence of functional Fe deficiency associated with overweight in these pre-schoolers is of concern, and highlights the importance of strengthening efforts to prevent the emerging problem of overweight in disadvantaged pre-schoolers in NE Brazil.

\section{Acknowledgements}

Sources of funding: The work was funded in part by the University of Otago Research Fund, but the Board administering the Fund had no role in the design of the study, the data analysis or the writing of this article. Conflicts of interest: None. Autbors' contributions: R.L.L. contributed to the research project design, conduct of the study, statistical analysis and manuscript draft; K.B.B., A.G.L. and A.A.A. contributed to the analysis of the specimens; H.C.C.-R. and A.P.M. contributed to the research study oversight and recruitment of the day-care centres; D.B.L. assisted with the conduct of the study; L.A.H. and I.M.M. provided oversight of analytical procedures and contributed to the manuscript draft; S.M.W. contributed to the statistical analysis and manuscript draft; R.S.G. contributed to the research project design, study oversight and manuscript draft. All authors have read and approved the final draft. Acknowledgements: The authors thank the daycare organizations Santa Casa de Misericordia and Mansão do Caminho for their support during planning and implementation of this study, the parents of the participating children, and the coordinators of the seven day-care centres. They also thank all nutritionists from the Fima Lifshitz Research Unit of the Hospital Universitário Professor Edgard Santos who assisted with the data collection.

\section{References}

1. UNICEF (2012) Children in an Urban World. State of the World's Children 2012. New York: UNICEF.

2. Prado M, Strina A, Barreto M et al. (2003) Risk factors for infection with Giardia duodenalis in pre-school children in the city of Salvador, Brazil. Epidemiol Infect 131, 899-906.

3. Assis A, Barreto M, Gomes G et al. (2004) Childhood anemia prevalence and associated factors in Salvador, Bahia, Brazil. Cad Saude Publica 20, 1633-1641.

4. Martins M, Santos L \& Assis A (2004) Prevalence of hypovitaminosis A among preschool children from northeastern Brazil, 1998. Rev Saude Publica 38, 537-542.

5. Grantham-McGregor S, Cheung Y, Cueto S et al. (2007) Developmental potential in the first 5 years for children in developing countries. Lancet 369, 60-70.

6. Antunes M, Sichieri R \& Salles-Costa R (2010) Food intake among children under three years of age in an area with high food insecurity. Cad Saude Publica 26, 1642-1650.

7. Barreto M, Genser B, Strina A et al. (2010) Impact of a citywide sanitation program in northeast Brazil on intestinal parasites infection in young children. Environ Health Perspect 118, 1637-1642.

8. Müller N \& von Allmen N (2005) Recent insights into the mucosal reactions associated with Giardia lamblia infections. Int J Parasitol 35, 1339-1347.

9. Instituto Brasileiro de Geografia e Estatística (2010) Census 2010. Rio de Janeiro: IBGE.

10. Bain B (2006) Haemoglobinopathy Diagnosis, 2nd ed. Oxford: Blackwell Publishing.

11. Zemel B, Kawchak D, Fung E et al. (2002) Effect of zinc supplementation on growth and body composition in children with sickle cell disease. Am J Clin Nutr 75, 300-307.

12. Fung E (2010) Nutritional deficiencies in patients with thalassemia. Ann N Y Acad Sci 1202, 188-196.

13. Brazil Ministry of Health (2007) Deficiencies of Micronutrients. Cadernos de Atencao Basica. Brasilia: Ministry of Health.

14. Brazil Ministry of Health (1996) Public Law on the Rights and Basis of Education. Law 9.394, December 20, 1996. Brasilia: Ministry of Health.

15. Lander R, Lander A, Houghton L et al. (2012) Factors influencing growth and intestinal parasitic infections in preschoolers attending philanthropic daycare centers 
in Salvador, Northeast region of Brazil. Cad Saude Publica 28, 2177-2188.

16. Lander R (2012) The nutritional status of disadvantaged preschool children attending daycares in Salvador, Northeast Brazil: a cross-sectional study. PhD Thesis, University of Otago.

17. Issler R, Guigliani E, Kreutz G et al. (1996) Poverty levels and children's health status: study of risk factors in an urban population of low socioeconomic level. Rev Saude Publica 30, 506-511.

18. WHO Multicentre Growth Reference Study Group (2006) WHO child growth standards based on length/height, weight and age. Acta Paediatr 95, 76-85.

19. de Onis M, Onyango AW, Borghi E et al. (2007) Development of a WHO growth reference for school-aged children and adolescents. Bull World Health Organ 85, 660-667.

20. Tamura T, Johnston K, Freeberg L et al. (1994) Refrigeration of blood samples prior to separation is essential for the accurate determination of plasma or serum zinc concentrations. Biol Trace Elem Res 41, 165-173.

21. Thurlow R, Winichagoon P, Green T et al. (2005) Only a small proportion of anemia in northeast Thai children is associated with iron deficiency. Am J Clin Nutr 82, 380-387.

22. Smith J, Butrimovitz G \& Purdy W (1979) Direct measurement of zinc in plasma by atomic absorption spectroscopy. Clin Chem 25, 1487-1491.

23. Jacobson B \& Lockitch G (1988) Direct determination of selenium in serum by graphite-furnace atomic absorption spectrometry with deuterium background detection and a reduced palladium modifier: age specific reference ranges. Clin Chem 34, 709-714.

24. Thurnham D, Smith E \& Flora P (1988) Concurrent liquid-chromatographic assay of retinol, $\alpha$-tocopherol, $\beta$-carotene, $\alpha$-carotene, lycopene, and $\beta$-cryptoxanthin in plasma with tocopherol acetate as an internal standard. Clin Chem 34, 377-381.

25. Molloy A \& Scott J (1997) Microbiological assay for serum, plasma, and red cell folate using cryopreserved, microtitre plate method. Meth Enzymol 281, 43-53.

26. Tan A, Quah T, Low P et al. (2001) A rapid and reliable 7-deletion multiplex polymerase chain reaction assay for alpha thalassemia. Blood 98, 250-251.

27. Alsaleh A (2011) Haemoglobinopathies and thalassemia among Brazilian children: a cross-sectional study. Masters Dissertation, University of Otago.

28. World Health Organization (2001) Iron Deficiency Anaemia: Assessment, Prevention and Control - A Guide for Programme Managers. Geneva: WHO.

29. Gibson R (2005) Principles of Nutritonal Assessment, 2nd ed. Oxford: Oxford University Press.

30. Cook J, Skikne B \& Baynes R (1993) Serum transferrin receptor. Annu Rev Med 44, 63-74.

31. Hotz C, Peerson J \& Brown K (2003) Suggested lower cutoffs of serum zinc concentrations for assessing zinc status: reanalysis of the second National Health and Nutrition Examination Survey data (1976-1980). Am J Clin Nutr $\mathbf{7 8}$, 756-764.

32. Thomson C (2004) Assessment of requirements for selenium and adequacy of selenium status: a review. Eur $J$ Clin Nutr 58, 391-402.

33. de Pee S \& Dary O (2002) Biochemical indicators of vitamin A deficiency: serum retinol and serum retinol binding protein. J Nutr 132, 9 Suppl., 2895S-2901S.

34. de Benoist B (2008) Conclusions of a WHO technical consultation on folate and vitamin $\mathrm{B}_{12}$ deficiencies. Food Nutr Bull 29, 2 Suppl., S238-S244.

35. Ballew C, Bowman B, Sowell A et al. (2001) Serum retinol distributions in residents of the United States: third National
Health and Nutrition Examination Survey, 1988-1994. Am J Clin Nutr 73, 586-593.

36. Pfeiffer C, Johnson C, Jain R et al. (2007) Trends in blood folate and vitamin B-12 concentrations in the United States, 1988-2004. Am J Clin Nutr 86, 718-727.

37. Thurnham D, Mburu A, Mwaniki D et al. (2005) Micronutrients in childhood and the influence of subclinical inflammation. Proc Nutr Soc 64, 502-509.

38. World Health Organization/Centers for Disease Control and Prevention (2007) Assessing the Iron Status of Populations, 2nd ed. Geneva: WHO.

39. Thurnham D, McCabe G, Northrop-Clewes C et al. (2003) Effects of subclinical infection on plasma retinol concentrations and assessment of prevalence of vitamin A deficiency: meta-analysis. Lancet 362, 2052-2058.

40. Thurnham D, McCabe L, Haldar S et al. (2010) Adjusting plasma ferritin concentrations to remove the effects of subclinical inflammation in the assessment of iron deficiency: a meta-analysis. Am J Clin Nutr 92, 546-555.

41. Vieira A, Diniz A, Cabral P et al. (2007) Nutritional assessment of iron status and anemia in children under 5 years old at public daycare centers. J Pediatr (Rio J) $\mathbf{8 3}$, 370-376.

42. Jordão R, Bernardi J \& Filho A (2009) Prevalence of irondeficiency anaemia in Brazil: a systematic review. Rev Paul Pediatr 27, 90-98.

43. Assunção M, Santos I, Barros A et al. (2012) Flour fortification with iron has no impact on anaemia in urban Brazilian children. Public Health Nutr 15, 1796-1801.

44. Paiva A, Rondo P, Gonçalves-Carvalho C et al. (2006) Prevalence and factors associated with vitamin A deficiency in preschool children from Teresina, Piaui, Brazil. Cad Saude Publica 22, 1979-1987.

45. Muñoz E, Rosado J, Lopez P et al. (2000) Iron and zinc supplementation improves indicators of vitamin A status of Mexican preschoolers. Am J Clin Nutr 71, 789-794.

46. Fishman S, Christian P \& West KJ (2000) The role of vitamins in the prevention and control of anaemia. Public Health Nutr 3, 125-150.

47. Mostert V, Hill K \& Burk R (2003) Loss of activity of the selenoenzyme thioredoxin reductase causes induction of hepatic heme oxygenase-1. FEBS Lett 541, 85-88.

48. Nagababu E, Chrest F \& Rifkind J (2003) Hydrogenperoxide-induced heme degradation in red blood cells: the protective roles of catalase and glutathione peroxidase. Biochim Biophys Acta 1620, 211-217.

49. Yanoff L, Menzie C, Denkinger B et al. (2007) Inflammation and iron deficiency in the hypoferremia of obesity. Int $J$ Obes (Lond) 31, 1412-1419.

50. Solomons N (1993) Pathways to the impairment of human nutritional status by gastrointestinal pathogens. Parasitology 107, Suppl., S19-S35.

51. Allen L, Rosado J, Casterline J et al. (1995) Vitamin B-12 deficiency and malabsorption are highly prevalent in rural Mexican communities. Am J Clin Nutr 62, 1013-1019.

52. dos Reis J, de Morais M, Oliva C et al. (2007) Breath hydrogen tests in the diagnosis of environmental enteropathy in children living in an urban slum. Dig Dis Sci 52, 1253-1258.

53. Sousa M, Gonçalves C, Bairos V et al. (2001) Adherence of Giardia lamblia trophozoites in Int- 407 human intestinal cells. Clin Diagn Lab Immunol 8, 258-265.

54. Khademi R, Ghaffarifar F \& Asl H (2006) In vitro effect of folic acid and cobalamin (vitamin $\mathrm{B}_{12}$ ) on adhesion and growth of Giardia lamblia. Iran J Parasitol 1, 47-52.

55. Smith A (2010) Folic acid nutrition: what about the little children? Am J Clin Nutr 91, 1408-1410.

56. Troen A, Mitchell B, Sorensen B et al. (2006) Unmetabolized folic acid in plasma is associated with reduced natural killer cell cytoxicity among postmenopausal women. J Nutr 136, 189-194. 